\title{
Penerapan Teknologi Rich Internet Application pada Proses Tracer Alumni STMIK Atma Luhur Berbasis Website
}

\author{
Delpiah Wahyuningsih ${ }^{\# 1}$, Yohanes Setiawan ${ }^{\# 2}$ \\ \# Jurusan Teknik Informatika, STMIK Atma Luhur Pangkalpinang \\ Jln Selindung Kel Selindung Kec Gabek Pangkalpinang \\ 1 delphibabeleatmaluhur.ac.id \\ ysetiawanj@atmaluhur.ac.id
}

\begin{abstract}
Abstrak- Pada STMIK Atma Luhur Pangkalpinang, pengumpulan data alumni tidak berjalan dengan baik. Sampai saat ini, data alumni hanya tersedia dalam buku alumni. Bagian Kemahasiswa memiliki buku alumni yang data hanya dikumpulkan sekali sebelum kelulusan mereka, sehingga data alumni yang diperoleh tidak up-to-date. Dengan tracer alumni secara online untuk pengumpulan data alumni, sehingga Bagian Kemahasiswa mendapatkan data alumni secara up-todate dan bagian kemahasiswaan memperoleh informasi mengenai status alumni kerja atau sebaliknya. Tracer alumni secara online merupakan fasilitas meringankan bagian kemahasiswaan dalam memperoleh data alumni secara up-todate. Selain itu, alumni dapat mengetahui informasi tentang lowongan kerja dan pelatihan yang diterbitkan oleh admin.
\end{abstract}

Kata Kunci- tracer alumni, website, rich internet application, alumni atma luhur.

\section{Pendahuluan}

Perkembangan teknologi pada saat ini berkembang dengan sangat pesat. baik pada institusi pemerintahan perusahaan besar serta dalam dunia pendidikan. Dari kebutuhan primer hingga kebutuhan sekunder tidak terlepas dari teknologi, terutama pada dunia pendidikan hingga ke perguruan tinggi baik negeri maupun swasta. Sehingga setiap individu membutuhkan suatu informasi yang akurat, efektif dan efisien semakin meningkat, untuk memenuhi kebutuhan tersebut manusia terus berpikir untuk mengembangkan suatu teknologi yang dapat membantu manusia dalam hal pengolahan data, sehingga informasi yang diinginkan bisa didapatkan.

Salah satu cara untuk mendapatkan informasi dengan cepat adalah penggunaan website. Dengan adanya website dapat memenuhi informasi yang dibutuhkan oleh institusi pendidikan negeri maupun swasta, salah satu pendidikan swasta yaitu STMIK Atma Luhur Pangkalpinang.

STMIK Atma Luhur mempunyai banyak alumni yang tersebar luas, terutama di Kepulauan Bangka Belitung. Alumni Atma Luhur tersebut yang dari awal hingga saat ini belum terdata secara up to date, misalnya mengenai pekerjaan, nomor handphone yang bisa dihubungi. Dari berdirinya Atma Luhur hingga saat ini hanya ada buku alumni, sedangkan buku alumni tersebut hanya dipegang oleh alumni dan pihak institusi. Disaat alumni ataupun pihak institusi membutuhkan data alumni atau menghubungi alumni untuk keperluan sulit mendapatkan informasi yang dibutuhkan. Dengan ini dibutuhkan suatu sistem berbasis web yang efektif, efisien dan up to date dalam penggunaannya, sehingga dapat mempermudah alumni ataupun pihak institusi.

Sistem berbasis website dengan penerapan rich internet application ini bukan hanya memberikan sebuah informasi pekerjaan ataupun nomor handphone tetapi juga memberikan informasi lowongan pekerjaan dan pelatihan untuk alumni yang belum bekerja dan alumni yang membutuhkan pelatihan. Sehingga sistem ini mempermudah alumni ataupun pihak institusi dalam memperoleh informasi yang efektif, efisien dan up to date.

\section{URAIAN PENELITIAN}

\section{A. Rich Internet Application}

Rich Internet Application (RIA), merupakan aplikasi web yang memiliki fitur dan fungsi seperti aplikasi desktop, RIA dapat berjalan pada web browser biasa tanpa harus memerlukan software tertentu [1].

Rich Internet Application (RIA), adalah aplikasi web yang memiliki beberapa karakteristik dari aplikasi desktop, typpically disampaikan dengan cara proprietary web browser plug-in atau mandiri melalui kotak pasir atau mesin virtual. Contoh kerangka RIA termasuk adobe flex/air. java/javafx. unipaas and microsoft sillverlight [2].

Rich Internet Application yaitu aplikasi web yang sebagian besar karakteristiknya diambil dari aplikasi desktop. Contoh 
RIA framework adalah curl, GWT, Adobe Flash/Adobe, Flex/AIR, Java/JavaFX, Mozilla XUL dan Microsoft Silverlight [3].

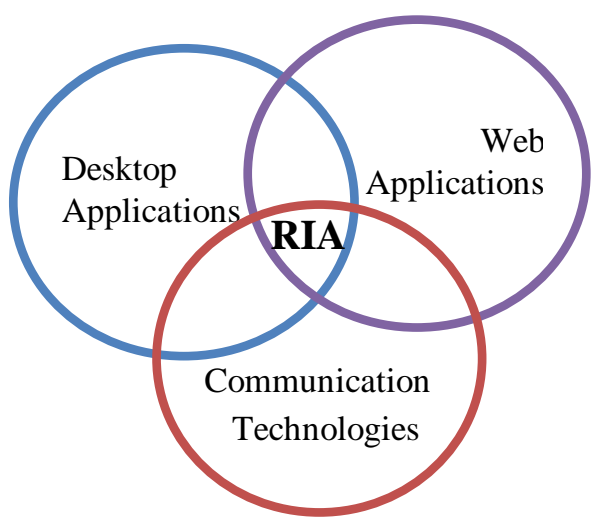

Gambar 1. Diagram Rich Internet Application [3]

Gambar 1 menjelaskan diagram RIA, di mana teknologi RIA menggabungkan antara desktop application, web application, dan communication technologies. Beberapa karakteristik RIA secara umum, antara lain responsif. Sebagai aplikasi web, RIA memiliki perbedaan yang amat mencolok dengan web konvensional. RIA tidak melakukan reload halaman ketika suatu tombol atau link dipilih. RIA hanya melakukan update bagian-bagian tertentu ketika melakukan suatu aksi. Sementara pada web konvensional, halaman akan di update secara keseluruhan ketika melakukan suatu aksi. Dengan memanfaatkan RIA, user dapat melakukan kegiatan seperti apa yang dilakukan pada aplikasi desktop. Tingkat interaktifitas yang tinggi memungkinkan developer untuk memindahkan fitur-fitur pada sebuah aplikasi desktop ke dalam aplikasi web. Telah banyak aplikasi RIA yang dapat dimanfaatkan, sebagai contoh word processor, instant mesegger, dan sebagainya. RIA dapat dijalankan pada sistem operasi manapu dengan spesifikasi hardware yang tidak harus tinggi. Asalkan sistem operasi dapat menjalankan browser maka RIA dapat dijalankan dengan baik [4].

\section{Kelebihan RIA dibandingkan Web Statis}

Aplikasi web statis adalah web yang tampilan user interfacenya hanya dihasilkan dari kode-kode HTML saja. Untuk aplikasi web yang dibangun dengan menerapkan teknologi RIA memiliki kelebihan-kelebihan diantaranya:

\section{a) Richer}

RIA tidak hanya menawarkan halaman antarmuka yang dihasilkan dari file html, tetapi dengan fungsi ini, maka dapat memasukkan sesuatu yang dapat diimplementasikan pada teknologi yang digunakan pada sisi client, seperti drag dan drop, menggunakan slider untuk mengubah data, perhitungan dapat dilakukan di computer client.

\section{b) Responsif}

Membuat respon halaman web lebih cepat dengan cara tidak merubah (me-load) seluruh halaman web, tetapi hanya sebagian kecil dari informasi yang diperlukan saja.

\section{c) Komunikasi Asychronous}

Saat user pertama kali melakukan aktifitas di client maka client mengirimkan request kepada server dan server akan memberikan respon dari hasil request yang sudah dikirimkan oleh client. Selama proses tersebut interface pada client tidak ada pengaruh sama sekali. Ketika melakukan aktifitas selanjutnya client hanya mengirimkan request yang dibutuhkan saja, karena request-request yang sudah dikirimkan pada aktifitas pertama kali, disimpan dalam engine sementara. Hal ini menyebabkan client tidak sepenuhnya bergantung dengan server.

\section{B. Prototype}

Prototipe adalah proses interaktif dan berulang dengan menggabungkan langkah-langkah.

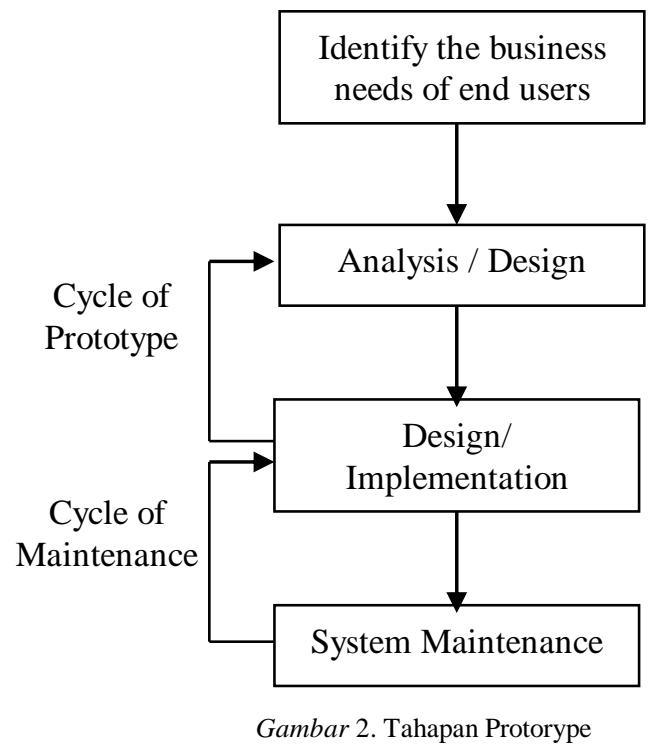

Pada Gambar 2. pengguna akhir mengidentifikasi kebutuhan bisnis dan menilai kelayakan beberapa solusi alternatif sistem informasi. Kemudian, pengguna akhir dan / atau sistem informasi pakar menggunakan alat pengembangan aplikasi secara interaktif merancang dan menguji prototipe dari berbagai komponen dari sistem informasi untuk memenuhi kebutuhan pengguna akhir. Sedangkan, pada tahap desain / implementasi, sistem bisnis prototipe diuji, dievaluasi, dan dimodifikasi berulang kali, sampai pengguna akhir dapat menerimanya. Pada tahap ini pelaksanaan / pemeliharaan, sistem bisnis dapat dimodifikasi 
dengan mudah diterima karena sebagian besar dokumentasi disimpan dalam sistem disk [5].

\section{Penelitian Sebelumnya}

Ada beberapa penelitian yang terkait yaitu pertama dengan judul "Perancangan dan Implementasi Aplikasi Pembelajaran Siklus Carnot Berbasis RIA untuk Pelajar SMA" dengan hasil dimana pelajar SMA dapat membantu pengguna, dalam hal ini siswa untuk memahami materi siklus carnot dengan melihat dan mengikuti materi dan animasi yang diberikan, membantu siswa mengetahui hasil belajar dengan melihat dan mengikuti evaluasi berdasarkan materi yang diberikan [6]. Kedua, dengan judul "Rich Internet Application (RIA) untuk aplikasi sistem informasi klinik kesehatan" dengan hasil RIA merupakan teknologi yang dapat menghubungkan agar perintah PHP dapat diterima oleh Flash, perlu dilakukan beberapa penyesuaian perintah. [7]

\section{Alumni STMIK Atma Luhur}

Sampai dengan tulisan ini dibuat, STMIK Atma Luhur Pangkalpinang memiliki lulusan dari 4 (empat) program studi yaitu: Teknik Informatika, Sistem Informasi, Manajemen Informatika, dan Komputerisasi Akuntansi. Tiap wisuda tahunan STMIK Atma Luhur, wisudawan diberikan sebuah buku alumni. Selain diberikan kepada alumni, buku alumni dibagikan kepada bagian kemahasiswaan sebagai arsip. Sayangnya, data yang terdapat pada buku alumni tersebut tidak up to date. Misalnya alumni yang pindah kerja atau ganti nomor handphone.

\section{E. Sistem yang diajukan}

Menjawab masalah di atas, maka diperlukan sebuah sistem yang dapat menampung data alumni secara up to date. Penulis mengusulkan sistem pendataan alumni secara online, untuk memudahkan alumni dalam mengisi data dan memudahkan bagian kemahasiswaan memperoleh data yang up to date.

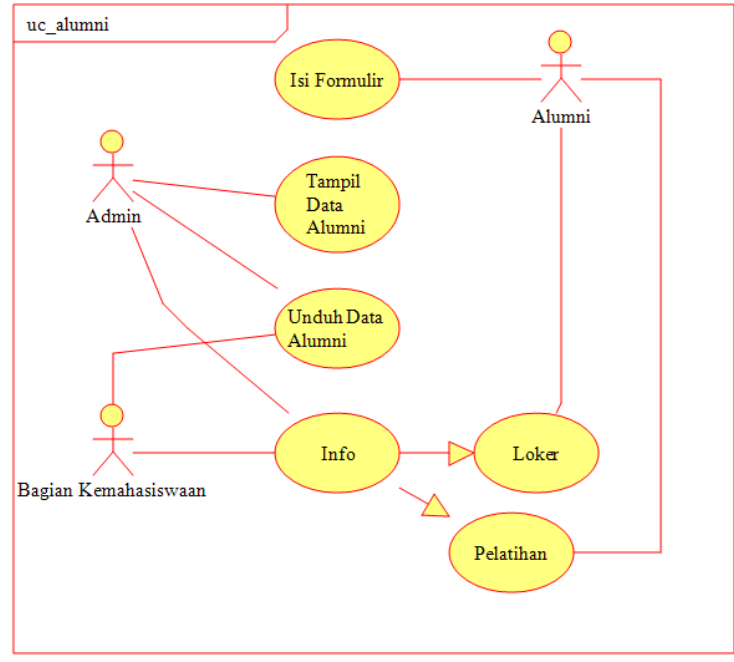

Gambar 3. Usecase Diagram Tracer Alumni

Sistem yang diajukan ini alumni melakukan pendaftaran untuk membuat akun alumni. Setelah mempunyai akun, alumni dapat memperoleh informasi secara up to date mengenai nomor telpon, alamat saat ini serta informasi mengenai lowongan pekerjaan dan pelatihan untuk alumni.

\section{HASIL}

Dari rancangan sistem yang telah diusulkan, kemudian dilakukan implementasi sistem pendataan alumni, dimana alumni dapat mengakses situs alumni STMIK Atma Luhur di alamat http://alumni.atmaluhur.ac.id.

Sistem Tracer alumni merupakan sebuah cara membantu bagian kemahasiswaan dalam mendata alumni STMIK Atma Luhur Pangkalpinang. Dimana Alumni mendaftar untuk menjadi alumni dan kemudian login dan mengklik link alumni untuk pengisian data alumni memalui media website. Sistem ini dengan perancangan teknologi rich internet application (RIA) dimana karekteristik dari RIA yaitu responsif dan interaktif.

Karekteristik RIA dari responsif tracer alumni terdapat pada form data alumni, pelatihan, loker, kontak. Sedangkan karakteristik RIA interaktif pada website tracer alumni ini dimana pada web ini menyediakan chat melalui facebook.

\section{A. Form Data Alumni}

Form data alumni yang terletak di bawah halaman alumni. Formulir ini diisi oleh alumni Atma Luhur yang berfungsi untuk pengumpulan data alumni. 


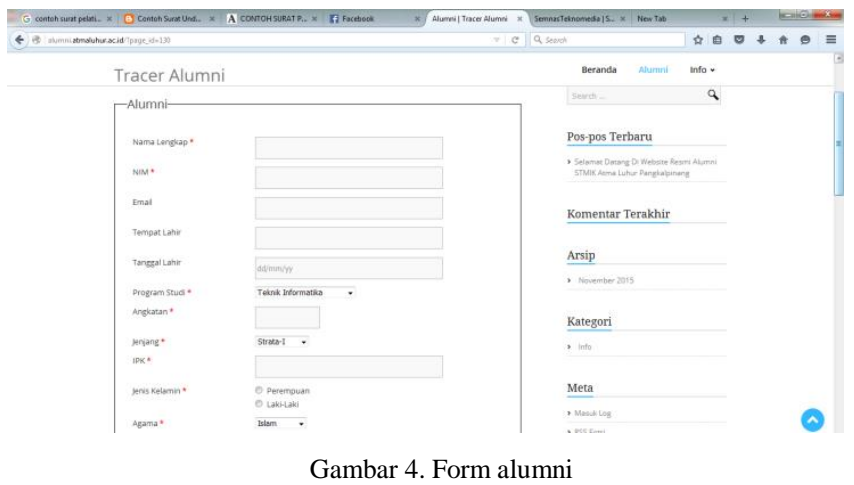

Pada gambar 4 menjelaskan dimana fungsi dari karakteristik RIA responsif dimana data yang diisi tetap mereload di halaman yang sama.

\section{B. Download Data Alumni}

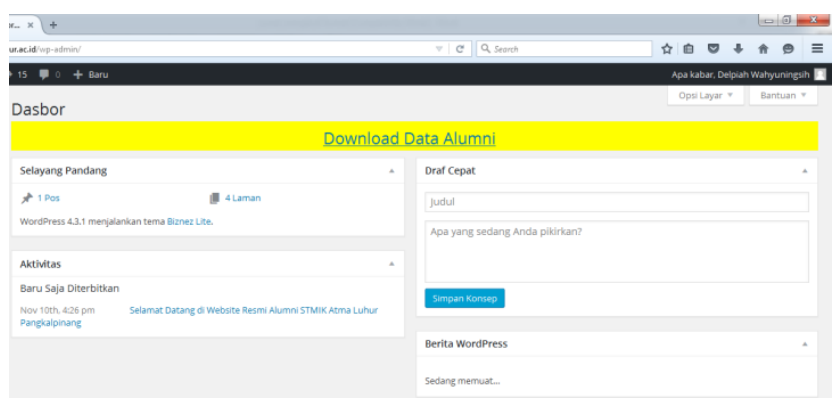

Gambar 5. Formulir Alumni

Pada gambar 5 menjelaskan dimana bagian kemahasiswaan yang sebagai user dapat mendownload data alumni yang telah di isi pada tahap awal. Dari data alumni ini, bagian kemahasiswaan dapat mengetahui seberapa lama masa tunggu kerja mahasiswa setelah lulus, mengetahui alumni bekerja di bidang mana saja.

\section{Informasi Lowongan Kerja dan Pelatihan}

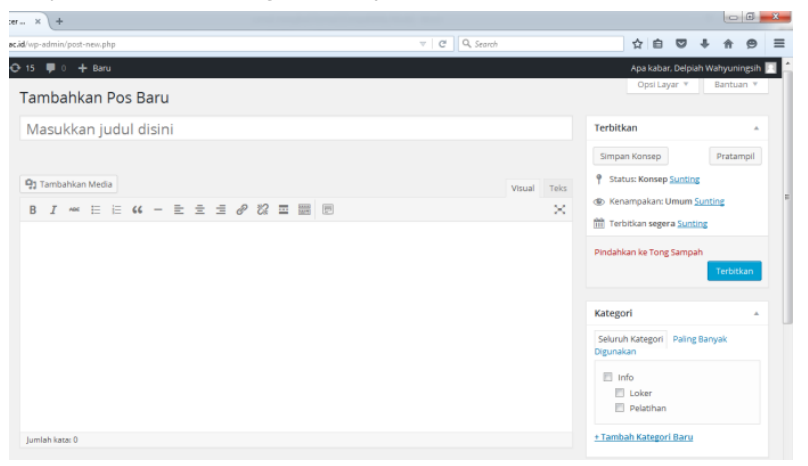

Gambar 6. Halaman Informasi lowongan kerja dan Pelatihan

Gambar 6 menunjukkan bagaimana Bagian Mahasiswa sebagai pengguna dengan peran admin dapat menambahkan informasi tentang lowongan pekerjaan atau pelatihan di halaman alumni website http://alumni.atmaluhur.ac.id

\section{Uji Program}

Pengujian program akan dilakukan dengan pengujian black box. Pengujian perangkat lunak menggunakan data uji berdasarkan data yang terdapat pada STMIK Atma Luhur Pangkalpinang.

Pengujian ini di implementasikan kepada pihak pengguna bagian kemahasiswaan dan beberapa alumni.

TABEL 1

Pengujian Sistem PendataAn Alumni Bagian KemahasiswaAn

\begin{tabular}{|c|l|l|l|c|}
\hline \multicolumn{5}{|c|}{ Hasil Pengujian } \\
\hline No & Menu & \multicolumn{1}{|c|}{$\begin{array}{c}\text { Yang } \\
\text { diharapkan }\end{array}$} & \multicolumn{1}{c|}{ Pengamatan } & Ket \\
\hline \multirow{2}{*}{2} & Login & $\begin{array}{l}\text { Username dan } \\
\text { password } \\
\text { tercantum } \\
\text { dalam form } \\
\text { isian }\end{array}$ & $\begin{array}{l}\text { Dapat mengisi } \\
\text { field tersebut dan } \\
\text { mengakses sistem } \\
\text { alumni }\end{array}$ & Diterima \\
\hline \multirow{2}{*}{3} & $\begin{array}{l}\text { Mengisi form } \\
\text { loker dan } \\
\text { menampilkan } \\
\text { ke kategori } \\
\text { loker }\end{array}$ & $\begin{array}{l}\text { Dapat mengisi } \\
\text { form loker dan } \\
\text { menampilkan } \\
\text { perkategori. }\end{array}$ & Diterima \\
\hline Pelatihan & $\begin{array}{l}\text { Mengisi firm } \\
\text { pelatihan dan } \\
\text { menampilkan } \\
\text { ke kategori }\end{array}$ & $\begin{array}{l}\text { Dapat mengisi } \\
\text { dorm loker dan } \\
\text { menampilkan } \\
\text { pelatihan yang } \\
\text { akan } \\
\text { diselenggarakan. }\end{array}$ & Diterima \\
\hline Unduh & $\begin{array}{l}\text { Menampilkan } \\
\text { data } \\
\text { alumni }\end{array}$ & $\begin{array}{l}\text { Dapat } \\
\text { menampilkan } \\
\text { berbentuk excel } \\
\text { laporan berbentuk } \\
\text { excel }\end{array}$ & Diterima \\
\hline
\end{tabular}

Pada Tabel I telah dilakukan pengujian sistem kepada bagian kemahasiswaan yang berperan sebagai admin. Semua data telah di cek satu persatu, semua telah diterima oleh pihak admin.

Untuk pengujian alumni dilakukan kepada beberapa alumni sebelum sistem ini di publikasi ke website. Dapat dilihat pada Tabel II hasil dari pengujian sistem oleh alumni. 
TABEL 2

PenguJian Sistem PendataAn Alumni Oleh Alumni

\begin{tabular}{|c|c|l|l|c|}
\hline \multicolumn{5}{|c|}{ Hasil Pengujian } \\
\hline No & Menu & $\begin{array}{c}\text { Yang } \\
\text { diharapkan }\end{array}$ & \multicolumn{1}{|c|}{ Pengamatan } & Ket \\
\hline 1 & Formulir & $\begin{array}{l}\text { Mengisi } \\
\text { formulir alumni }\end{array}$ & $\begin{array}{l}\text { Dapat mengisi } \\
\text { formulir alumni }\end{array}$ & Diterima \\
\hline 2 & $\begin{array}{l}\text { Info } \\
\text { Loker }\end{array}$ & $\begin{array}{l}\text { Melihat } \\
\text { informasi } \\
\text { lowongan kerja }\end{array}$ & $\begin{array}{l}\text { Dapat melihat } \\
\text { informasi } \\
\text { lowongan kerja }\end{array}$ & Diterima \\
\hline 3 & $\begin{array}{c}\text { Info } \\
\text { Pelatihan }\end{array}$ & $\begin{array}{l}\text { Melihat } \\
\text { informasi } \\
\text { pelatihan }\end{array}$ & $\begin{array}{l}\text { Dapat melihat } \\
\text { informasi } \\
\text { pelatihan }\end{array}$ & Diterima \\
\hline
\end{tabular}

\section{KESIMPULAN}

1. Sistem pendataan alumni dapat mempermudah dalam mengisi data terbaru, melihat informasi lowongan pekerjaan dan pelatihan.

2. Sistem pendaatan alumni dapat mempermudah bagian kemahasiswaan dalam memperoleh data alumni secara up to date.

\section{DAFTAR PUSTAKA}

[1] Asri, Yessi dan Anggi Puspita Sari. Jurnal: Implementasi Teknologi RIA dalam Pengembangan Antar Muka Berbasis Web menggunakan EXT JS Frame Work. Jurnal Pengkajian dan Penerapan Teknik Informatika Vol 2 No 12009.

[2] Busch, Marianne and Nora Koch. Rich Internet Applications State of the Art. Germany:Ludwig Maximilians Universitat Munchen (LMU). 2009.

[3] Deitel, Paul J., Deitel, Harvey M. Ajax Rich Internet Applications and Web Development for Programmers: Prentice Hall. 2008.

[4] Muda, Winnerrist Zarus, dkk. Perancangan dan Implementasi Sistem Katalog Buku Menggunakan RIA (Rich Internet Application). Teknologi Informasi, Universitas Kristen Satya Wacana. 2013.

[5] M. Shalahuddin dan Rosa, Rekayasa Perangkat Lunak Terstruktur dan Berorientasi Objek, Bandung: Modula, 2011.

[6] Imron, Mochamad Samsudin, dkk. Jurnal: Perancangan dan Implementasi Aplikasi Pembelajaran Siklus Carnot Berbasis RIA untuk Pelajar SMA. Jurnal Teknologi Informasi-Aiti Vol 11 No 1 Februari 2014.

[7] Noviyanto, fiftin dan Danang Dwi Wahyu Jati. Jurnal: Rich Internet Application (RIA) untuk Aplikasi Sistem Informasi Klinik Kesehatan. Jurnal Informatika Vol 3 No 2 Juli 2009. 